\title{
Scale and Dynamics of Overweight and Obesity Epidemic in Croatia
}

\author{
Ivana Kolcic Ozren Polašek Silvije Vuletić \\ Andrija Stampar School of Public Health, Zagreb, Croatia
}

The prevalence of overweight and obesity is showing a strong increasing trend in most countries. We aimed to investigate the scale and dynamics of the overweight and obesity epidemic in Croatia by comparing the data from the Croatian Health Survey (CHS) from 1997-1999 (N = 5,048) with the Croatian Adult Health Survey (CAHS) from 2003 ( $\mathrm{N}=$ $9,070)$. Weighted data from the CAHS were used based on a complex 7-step scheme employed to ensure the creation of representative sample of the adult Croatian population in terms of regional, urban-rural and household characteristics and to adjust for nonresponders [1]. Both surveys were previously shown to be representative for the Croatian adult population, compared to the 2001 official Census data [2]. Genderand age group-stratified (18-34, 35-49, 50-64 and 65 and more years) prevalence of overweight and obesity were calculated in both surveys. Interestingly, the prevalence of overweight $\left(\mathrm{BMI} \geq 25 \mathrm{~kg} / \mathrm{m}^{2}\right)$ in men of all ages decreased from $45.7 \%$ in $1997-1999$ to $43.3 \%$ in $2003(-5.3 \%)$ while the prevalence of obesity (BMI $\left.\geq 30 \mathrm{~kg} / \mathrm{m}^{2}\right)$ increased from 12.6 to $20.2 \%(+60.3 \%)$. In women the prevalence of overweight increased from 31.6 to $33.6 \%(+6.3 \%)$ while the prevalence of obesity increased from 14.9 to $20.6 \%$ ( $+38.3 \%)$. However, the age-stratified prevalence of obesity showed the highest increase in the youngest age group (18-34 years) where the increase in men was $83.6 \%$ while in women the prevalence of obesity increased by $320 \%$, from 1.5 to $6.3 \%$. Notably, the estimates for the youngest age groups were based on sufficient sample sizes (a total of 1,398 and 1,414 respondents in the CHS and CAHS, respectively), thus reducing the possibility that these changes were the consequence of the small sample size. In contrast to commonly referred lack of information for policy on cardiovascular diseases [3], the results of this study suggest that the youngest adults (especially women) should be treated as a priority population group that requires substantial public health intervention aiming to reduce the epidemic of overweight and obesity. Without such an intervention, we are most likely to expect a substantial increase in the prevalence of obesity in the years to come. However, it should be pointed out that in some countries obesity rates recently have seemed to reach a plateau at a high level.

\section{Acknowledgements}

This study was supported by the Ministry of Science, Education and Sport of the Republic of Croatia project No: 108-1080135-0264.

\section{Disclosure}

The authors declared no conflict of interest.

\section{References}

1 Vuletic S, Polasek O, Kern J, Strnad M, Baklaic Z Croatian Adult Health Survey - a tool for periodic cardiovascular risk factor surveillance. Coll Antropol 2009;33(suppl 1):1-5.
Kolcic I, Polasek O: Do public health surveys provide representative data? Comparison of three different sampling approaches in the adult population of Croatia. Coll Antropol 2009;33(suppl 1):153158.
3 Kern J, Strnad M, Coric T, Vuletic S: Cardiovascular risk factors in Croatia: struggling to provide the evidence for developing policy recommendations. Br Med J 2005;331:208-210.

\section{KARGER}

Fax +497614520714

Information@Karger.de

www.karger.com (c) 2010 S. Karger GmbH, Freiburg 